\title{
Raulin Award Lecture: Wilson's Disease Therapy With Zinc and Tetrathiomolybdate
}

\author{
George J. Brewer* \\ Department of Human Genetics, University of Michigan, Ann Arbor, Michigan

\begin{abstract}
Zinc and tetrathiomolybdate, effective, nontoxic drugs, have now been added to the treatment of most phases of Wilson's disease. Zinc is used for maintenance as well as treating presymptomatic, pregnant, and pediatric patients. Tetrathiomolybdate is the choice for patients presenting with neurologic diseases. J. Trace Elem. Exp. Med. 13:51-61, 2000. ๑ 2000 Wiley-Liss, Inc.
\end{abstract}

Key words: Wilson's disease; zinc; tetrathiomolybdate; copper homeostasis

\section{INTRODUCTION}

Wilson's disease is an inherited, autosomal recessive disease of copper accumulation [1-3]. Patients present, generally between the ages of 10 and 40 years, with liver disease, neurological abnormalities, psychiatric symptoms, or some combination of these. The liver is the organ responsible for copper homeostasis. Humans take in about $1.0 \mathrm{mg}$ of copper/day, which is about $25 \%$ more than requirements [1]. The liver excretes the excess in the bile for loss in the stool. Wilson's disease patients are not able to excrete excess copper in the bile [4-6] due to a mutation in a gene called ATP7B [7-9], which is part of the liver's excretory pathway for copper.

Wilson's disease patients generally have a low blood ceruloplasmin $(\mathrm{Cp})$. Ceruloplasmin contains six molecules of copper and is the main copper-containing protein of the blood. A low blood Cp in Wilson's disease seems to carry no special clinical significance, since 10-20\% of Wilson's disease patients have a normal Cp, yet portray the same spectrum and severity of symptoms and abnormalites as do patients with a low $\mathrm{Cp}$. We have hypothesized that the low blood $\mathrm{Cp}$ and the failure in copper balance regulation are due to the same general mechanism [10]. In normal bile, but not in bile from Wilson's disease patients, we find copper-containing fragments of Cp molecules [10]. These fragments are resistant to proteolytic digestion and provide a packaging mechanism for copper to escape in the stool without reabsorption in the intestinal tract. Thus we postulate that the product of ATP7B plays a role in the maturation of $\mathrm{Cp}$, possibly such as copper addition, and that this failure of $\mathrm{Cp}$ maturation in Wil-

*Correpondence to: George J. Brewer, Department of Human Genetics, University of Michigan Medical School, Ann Arbor, MI 48109.

Received 1 June 1999; Accepted 30 September 1999

(C) 2000 Wiley-Liss, Inc. 
son's disease leads to low secretion of $\mathrm{Cp}$ into blood and low excretion of $\mathrm{Cp}$ into bile, the latter leading to loss of copper balance regulation [10].

Failure to recognize a possible diagnosis of Wilson's disease in a patient who truly has it is a worldwide problem. Physicians often fail to think of Wilson's disease because it is rare, because it can present with any one or a combination of a long list of symptoms and because it can masquerade as any one of many diseases that are much more common. The presenting symptoms and laboratory findings may suggest viral hepatitis, chronic active hepatitis, cirrhosis (including alcoholic cirrhosis), and liver failure [1-3]. Or the manifestations may include neurological symptoms, either singly or in combinations, such as dysarthria, tremor, dystonia, incoordination, Parkinsonism, or other symptoms typical of a movement disorder [11]. To further confuse the issue, the symptoms may be psychiatric in nature and include loss of ability to focus on tasks, extremes of emotionality, depression, delusions or hallucinations, and manic behavior. Thus, this plethora of modes of presentation causes Wilson's disease patients to be relatively hidden in much more common patient groups.

One of the keys in recognizing the possibility of Wilson's is to use relative youth to enhance index of suspicion. Many of the diseases with which Wilson's is confused are primarily diseases of people beyond 40 years, such as alcoholic cirrhosis, essential tremor, and Parkinsonism. In patients age 40 or less, any of the abnormalities noted above should cause the physician to think of the possibility of Wilson's disease and screen for it.

Which screening tests to use depends a little on the area of symptoms. In the neurologic or psychiatric presentation, a slit-lamp exam for Kayser-Fleischer (KF) $[12,13]$ rings (copper deposits in the cornea) is very useful because this type of patient almost always has KF rings. However, these rings are often absent in patients with the hepatic presentation, or in presymptomatic patients. (Presymptomatic patients are those usually identified by screening as a result of a diagnosis in a sibling. All full siblings of an affected person are at $25 \%$ risk of having the disease in a presymptomatic state. It is important to diagnose these patients because they should be treated prophylactically).

The 24-hour urine copper is a very valuable screening tool in that all symptomatically presenting patients have values over $100 \mu \mathrm{g}$ (normal is 20-50) [1]. False positives can occasionally be seen in long-standing or obstructive liver disease. Presymptomatic patients may not always have reached 100 [1]. Their values can range from 65 on up, and since gene carriers can have slightly elevated values, ranging from 75 on down, there is some overlap.

Blood ceruloplasmin (Cp) is low in about $90 \%$ of Wilson's disease patients, but some patients have normal Cp values. Since about $10 \%$ of gene carriers can have low $\mathrm{Cp}$ values, this test should be used only to affect index of suspicion about the disease.

Definitive diagnosis of Wilson's disease in some cases can be based on results of one or more of the above tests plus the clinical picture. For example, a patient with a typical neurologic picture who has KF rings needs no further diagnostic workup. A patient with behavioral symptoms, KF rings, and an elevated (over $100 \mu \mathrm{g} / 24$ hours) urine copper also has Wilson's disease. In all patients in whom there is doubt, and in most patients with liver disease, a liver biopsy with quantitative liver copper assay should be carried out. This is the gold standard for diagnosis. Affected patients, whether presymptomatic or not, will have values over $200 \mu \mathrm{g} / \mathrm{g}$ dry weight of liver. 
Normal is 20-50, and gene carriers are never over 125 . It is to be emphasized that the copper must be assayed quantitatively. Copper stains are not reliable for diagnosis.

\section{Treatment With Zinc and Tetrathiomolybdate}

Table I provides an organizational framework for anticopper therapy in Wilson's disease. When we began work on Wilson's disease a couple of decades ago, the two available drugs were penicillamine and trientine. Notice that a drug of long-standing use [14], penicillamine, is absent from Table I. Because of its toxicity [1], we almost never use it for treating Wilson's disease, the one exception being its possible use in fulminant hepatic failure when a liver transplant is not available, or is refused.

Trientine [15], which like penicillamine is a chelator that causes increased urinary excretion of copper, is a safer drug than penicillamine. It shares some of the same toxicities as penicillamine, but at a lower frequency. As of now, it is one of the two drugs we use for initial therapy of the hepatic presentation (Table I).

Our work has focused on the development of zinc and tetrathiomolybdate therapy for Wilson's disease, and we briefly review the use of these drugs.

\section{Zinc Therapy}

Our interest in using zinc as an anticopper drug in Wilson's disease stemmed from a serendipitous observation in sickle cell anemia. We were giving sickle cell patients high doses of zinc to inhibit sickling [16], when we discovered that about 3 months of therapy caused these patients to become mildly copper deficient [17,18]. As a geneticist, I was aware of Wilson's disease and the problems with penicillamine, and it occurred to me that perhaps we could develop zinc as a safer alternative. We then did copper balance and uptake studies with orally administered ${ }^{64}$ copper in patients in whom we temporarily stopped penicillamine and treated with the same dose and regimen of zinc we had used for sickle cell anemia [19]. When these studies showed that zinc therapy produced a negative copper balance and blocked ${ }^{64}$ copper absorption, we began the step-by-step development of zinc as a therapy in Wilson's disease [20-35].

In our early work we had to choose a salt of zinc with optimal properties. Zinc sulfate has been the standard salt used and was known to be well absorbed. However,

TABLE I. Organization of Anticopper Therapy in Wilson's Disease and Drug of Choice

\begin{tabular}{ll}
\hline Category of patient & \multicolumn{1}{c}{ Drug of choice } \\
\hline Initial Presentation (First 2-6 months) & \\
Psychiatric & Tetrathiomolybdate (2 months) \\
Neurologic & Tetrathiomolybdate (2 months) \\
Hepatic & Trientine and zinc, 4-6 months, then zinc alone \\
Maintenance & Zinc \\
Presymptomatic & Zinc \\
Pregnant & Zinc \\
Pediatric & Zinc \\
\hline
\end{tabular}


sulfate was known to be irritating to the stomach. We showed that zinc acetate was equally well absorbed, whereas zinc carbonate was somewhat inferior [36]. We later showed that zinc oxide is greatly inferior [37]. Thus all our work on Wilson's disease has been carried out with zinc acetate.

The copper balance and ${ }^{64}$ copper uptake data [19-21] told us that at any one point in time, i.e., during hospitalization, zinc controlled copper metabolism. But before we could place patients on zinc for any extended period of time, particularly during periods in the home environment, we needed monitoring tools that told us zinc was controlling copper under these conditions. We found that measuring 24-hour urinary excretion of copper was excellent for this purpose [23]. Without chelation therapy, urinary excretion of copper is a reflection of body loading of copper. Thus this variable gave us information on the cumulative effects of zinc therapy on reducing the body burden of copper. We found that in well-complying patients, urinary excretion of copper gradually decreases to a value $<125 \mu \mathrm{g} / 24$ hours, which reflects good control (normal is 20-50) [34].

Also useful is the nonceruloplasmin plasma copper value [23,34]. Ceruloplasmin (Cp) contributes substantially to plasma copper, but this copper is nontoxic. So a simultaneous measure of plasma copper and $\mathrm{Cp}$ is done and then the $\mathrm{Cp}$ copper subtracted from the plasma copper [2]. This is done by subtracting $3 \mu \mathrm{g}$ of copper for every $\mathrm{mg}$ of $\mathrm{Cp}$. Thus in a patient with a plasma copper of $30 \mu \mathrm{g} / \mathrm{dl}$, and a $\mathrm{Cp}$ of 5 $\mathrm{mg} / \mathrm{dl}$, the 5 is multiplied by 3 to give $15 \mu \mathrm{g}$ Cp copper/dl. Then the 15 is subtracted from 30 (total plasma copper) to give a value of $15 \mu \mathrm{g} / \mathrm{dl}$ for nonceruloplasmin plasma copper. Other names for this are "free copper" (although it's not free), "available copper," or "potentially toxic copper." In normal persons, the nonceruloplasmin plasma copper is around $10-15 \mu \mathrm{g} / \mathrm{dl}$. In untreated Wilson's disease, this pool is usually greatly expanded and is frequently 50 or higher. In our experience, when this pool of copper is brought below 25, the patient is under good control [34].

As soon as we had monitoring tools in place, we began to determine appropriate dose and dose regimens for zinc [20,25,27,31]. We established early that zinc had to be separated from most foods and most beverages other than water to be maximally effective. Thus we recommend separating zinc by at least 1 hour from the ingestion of substances other than water.

To investigate dose and regimens, we used a combination of 10-day copper balance studies and ${ }^{64}$ copper uptake studies $[20,25,27,31]$. We placed patients on the regimen to be studied for several weeks before the study to allow complete washout of former therapies. With no therapy we saw an average of $+0.25 \mathrm{mg} /$ day positive copper balance and high absorption of orally administered ${ }^{64}$ copper. A dose as low as $25 \mathrm{mg}$ of zinc/day reduced the average positive balance significantly but did not consistently control copper balance or ${ }^{64}$ copper uptake. The same can be said for $25 \mathrm{mg} \times 2,50$ $\mathrm{mg} \times 1$ and $75 \mathrm{mg} \times 1$. Interestingly, when we split the $75 \mathrm{mg}$ daily dose into two or three divided doses, such as $37.5 \mathrm{mg} \times 2$ or $25 \mathrm{mg} \times 3$, consistent control of copper balance and ${ }^{64}$ copper absorption was obtained; $50 \mathrm{mg} \times 2$ and $50 \mathrm{mg} \times 3$ were also effective doses. To provide a safety margin, our standard recommended adult dose is $50 \mathrm{mg} \times 3[1,34]$.

The mechanism of zinc action on copper metabolism received attention in animal studies by other investigators during the early years of zinc development as a therapy for Wilson's disease. The Cousins group in Florida [38, 39] and the Bremner group 
in Scotland [40] showed that zinc induces intestinal cell metallothionein, which has a high affinity for copper, and prevents the serosal transfer of copper. The bound copper goes into the stool as the mucosal cells of the intestine desquamate. Later, in collaboration with the Cousins group, we showed that this mechanism is also valid in Wilson's disease patients [29]. Using intestinal biopsies to obtain samples for metallothionein assay, we found that with zinc therapy, intestinal metallothionein levels increased in concert with blockade of ${ }^{64}$ copper absorption.

To evaluate the efficacy of zinc in Wilson's disease, we set up a protocol that required that all patients going on zinc therapy as their sole anticopper medication have an initial copper balance study and ${ }^{64}$ copper absorption study. Only with documentation that a given zinc regimen controlled copper did we feel safe in initiating long-term therapy. In our view, to do otherwise in the early stages of a trial such as this would be unethical, because known effective therapy (penicillamine and trientine) was available. We monitored efficacy and possible toxicity in these patients by following urine copper, liver copper, urine zinc, plasma zinc, nonceruloplasmin plasma copper, neurologic and speech function scores, blood counts, and other routine serum biochemical measures as safety variables at regular intervals. We used a mailin urine kit system to follow urine copper and zinc levels.

All patients started on zinc as part of this trial were followed and accounted for. In this sense, this study has become by far the largest and longest scientifically performed clinical trial of a therapy in Wilson's disease [34]. Most other reports of therapy or therapy trials in Wilson's disease are basically anecdotal in that if patients don't return to the clinic after therapy initiation, they're not used in the report.

We recently reported long-term follow-up studies on 141 patients treated with zinc [34]; 109 patients have been treated for 5 years or longer, and 46 patients for 10 years or longer. The efficacy data are excellent on all counts (34). The main problem has been inadequate compliance with therapy by some patients, a problem in any longterm trial. We detect noncompliance first by a urine zinc that is not as high as it should be, namely, a minimum of $2 \mathrm{mg} / 24$ hours. Later, if noncompliance continues, the urine copper begins to increase. Such evidence results in a series of calls and letters from our office, warning the patient about possible dangers of further noncompliance. We also increase the frequency of monitoring. Serious noncompliance occurred in about $10 \%$ of our patients, and periodic lessening of rigor in compliance occurred in another $20 \%$ [34].

In addition to the long-term follow-up of maintenance therapy in symptomatic patients who had originally been initiated on other therapies, our study included the successful treatment of 20 presymptomatic patients from the beginning with zinc as the sole therapy [34]. Since this is a genetic disease, it is important to screen other family members, particularly full siblings, who are at a $25 \%$ risk for being affected in a presymptomatic stage. These patients are considered as comparable to maintenance phase patients and are treated only with zinc [32,34].

We have also treated women with Wilson's disease through 18 pregnancies, using zinc alone as the anticopper drug. Results have been good [34]. It is important for these women to stay on anticopper therapy during pregnancy to protect themselves against disease remission. Penicillamine and trientine are teratogenic in animals [41], and penicillamine produces a teratogenic syndrome in human babies with a frequency of about 5\% [42, 43]. Zinc is nonteratogenic [44]. 
We have successfully treated 30 pediatric Wilson's disease patients with zinc as the maintenance anticopper drug, the youngest being 3 years of age $[34,35]$. We use a reduced dose $(25 \mathrm{mg} \times 2$ until age 6 , then $25 \mathrm{mg} \times 3$ until 16 years of age or 125 pounds body weight, then $50 \mathrm{mg} \times 3$ ). It is important to prevent overtreatment in pediatric patients, because copper is required for bone growth. We monitor for overtreatment in adults and pediatric patients, first by use of urine copper. When it reaches low normal (below $35 \mu \mathrm{g} / 24$ hours), we reduce the dose. The first clinical indication of copper deficiency is anemia.

The only toxicity of zinc we have encountered is mild to moderate abdominal discomfort in about $10 \%$ of patients [34]. In many patients, this disappears within a few days of therapy. In others, it is associated with taking the first dose upon arising. For the latter patients we advise taking the first dose at midmorning. For stubborn cases we allow the taking of offending doses with a little protein, such as lunchmeat, cheese, or jello. Usually these maneuvers work well. Only one patient dropped out of our study because of zinc intolerance.

Other authors have reported putative toxicities of zinc ranging from negative effects on lipid metabolism [45-47] to worries about pancreatitis and negative effects on immune function [46]. We have studied each of these areas $[24,28,33]$ and find that none are of concern in zinc therapy in Wilson's disease.

There are also occasional reports of zinc treatment failures in Wilson's disease [48, 49]. When looked at carefully, there is no evidence in these reports that the patient was actually taking their zinc, and in one case there was actually evidence that they were not taking it [48]. During our study, six of our patients died [34]. Three of these deaths occurred from complications of acute or chronic aspiration and subsequent infection. These data highlight the consequences of aspiration in patients with dysphagia. These patients should have had gastostomies, but refused. One patient died from complications related to variceal bleeding, a significant risk in patients with cirrhosis. One died in an accident, and one died from progressive liver failure. The latter patient was suspected of noncompliance by the family. Six patients dropped out of the study, and 10 were discharged because of lack of cooperation.

The Lemmon Company sponsored zinc acetate under the Orphan Drug Act. Later, Lemmon was purchased by Gate Pharmaceutical. Based primarily upon our data, Gate submitted a New Drug Application (NDA) to the U.S. Food and Drug Administration (FDA), and zinc acetate, under the trade name Galzin ${ }^{\circledR}$, was eventually approved for maintenance therapy of Wilson's disease in 1997.

Additional contributions to the use of zinc in Wilson's disease have come from the Netherlands. Schouwink [50] gave zinc to two Wilson's disease patients as part of his thesis work, although this work was never published in the general literature. Hoogenraad's group [51-53] later followed up one of Schouwink's patients and also gave zinc, as the sulfate salt, to additional patients.

In summary of the status of zinc therapy for Wilson's disease, zinc is taking its place as the treatment of choice for maintenance therapy, as well as for the treatment of the presymptomatic, pregnant, and pediatric patient, based on its complete efficacy and lack of toxicity.

\section{Treatment With Tetrathiomolybdate}

Although zinc is ideal for maintenance therapy, it is too slow acting to be optimal for patients presenting with acute copper toxicity. It takes an estimated 4-6 months of 
therapy for zinc to control copper and get copper levels below toxic thresholds. Meanwhile, we discovered that penicillamine poses a huge risk to patients presenting with brain-related symptomatology [54]. We found that about $50 \%$ of these patients are made neurologically worse by penicillamine initiation, and half of those, or $25 \%$ of the original sample, never recovered to pre-penicillamine baseline. The lives of some of these patients were disastrously ruined. The mechanism of this worsening may involve mobilization of hepatic copper and temporary further increases in brain copper.

Trientine is an unknown with respect to its potential for causing neurological worsening. On the one hand, it shares mechanism of action with penicillamine in that it mobilizes copper into the bloodstream and causes increases in urinary copper. On the other hand, it is a somewhat gentler drug than penicillamine. Experience is nil with respect to using it as an initial drug in neurologically presenting patients.

Because of this therapeutic hiatus, we have developed tetrathiomolybdate (TM) for the initial treatment of Wilson's disease patients presenting with neurologic or psychiatric symptoms. TM was discovered as a result of investigations in Australia and New Zealand, initiated because ruminants grazing on certain pastures developed a syndrome later recognized as copper deficiency [55-57]. In due course, the pastures were found to be high in molybdenum (Mo), and Mo given to ruminants was then shown to cause copper deficiency [58]. However, Mo given to rats was ineffective $[59,60]$. Later it was realized that the rich sulfur metabolism in the rumen was converting Mo into various thiomolybdates. Thiomolybdates given to rats were potent anticopper agents, with the tetra-substituted derivative (TM), the most active [61]. Mason's group has contributed much information on Mo, thiomolybdates, and copper interactions $[62,63]$.

TM is a very potent anticopper agent, and therefore very toxic, unless animals being studied are copper-supplemented [64-66]. Copper supplementation eliminates all side effects of TM, so all its toxicity is related solely to the production of copper deficiency. In fact, no side effect of TM in animals or humans other than copper deficiency has been observed. TM acts by forming a tripartite complex with copper and protein [62,64-67]. Given with food, it prevents the absorption of food and endogenously secreted copper. Give between meals it is absorbed into the blood and complexes nonceruloplasmin plasma copper with itself and albumin. This copper is nontoxic because it is unavailable for cellular uptake. The complexed copper is believed to be primarily eliminated via the bile [62].

In our TM study in Wilson's disease, we give TM in six divided doses, three times a day with meals, and three times a day between meals [68-70]. Although we have used higher doses in the past, currently we use $20 \mathrm{mg}$ of TM in each dose. Higher doses are more likely to produce a reversible anemia, which is due to bone marrow depletion of copper. We give the drug for 8 weeks, during which time we carefully monitor neurologic and speech function weekly with quantitative tests, to be sure neurologic deterioration is not occurring. Zinc is started either at the beginning, or at the 6 week point. At the end of 8 weeks, TM is stopped and the patient continues on zinc therapy for maintenance.

Clinical results have been excellent with using TM in this manner [68-70]. Only 2 of 56 patients reached minimal scoring criteria for neurological worsening, and these were minor. Clinical recovery begins about 5-6 months after therapy initiation and continues for about 18 months. Almost all patients show substantial recovery, and 
often dramatic recovery. Residual deficits present 24 months after therapy initiation are usually permanent.

In summary of the status of TM treatment for Wilson's disease, it has proven to be an ideal therapy for the initial treatment of neurologically presenting patients. It gains control of copper quickly and without toxicity. So far, we have not found a commercial sponsor for this drug. The market is tiny, keeping in mind that neurologically presenting patients (estimated to about 200/year in the United States) are treated for only 8 weeks. At present, we are doing a double- blind comparison of TM and trientine for initial therapy in these patients, in collaboration with Dr. Michael Schilsky of Mount Sinai Medical Center, NY. If it turns out that trientine does not share penicillamine's risk of inducing neurological worsening, TM may not be needed. However, if TM is significantly better than trientine in protecting function, it will be important to find commercial sponsorship and put TM through the FDA approval process.

This leaves as the only area of treatment not discussed, the treatment of patients presenting with hepatic disease. First, if this type patient is in moderate to severe hepatic failure, a decision needs to be made as to whether to recommend hepatic transplantation or medical therapy. We find the prognostic index of Nazer et al. [71] to be helpful as one guide in that decision-making process. If medical therapy is opted for, we use a combination of trientine and zinc. Trientine is given to provide a sizeable, fast, negative copper balance and zinc is given at this stage to induce hepatic metallothionein, which will sequester hepatic copper and render it nontoxic.

In summary, with zinc and tetrathiomolybdate added to our therapeutic armamentorium, we now have very effective, nontoxic drugs to treat most phases of Wilson's disease. Zinc is the drug of choice for maintenance and for treatment of presymptomatic, pregnant, and pediatric patients. Tetrathiomolybdate is excellent for the patient presenting with neurologic disease. We have successfully used a combination of trientine and zinc for the initial treatment of the patient presenting with hepatic disease.

\section{REFERENCES}

1. Brewer GJ, Yuzbasiyan-Gurkan V. Wilson disease. Medicine 1992;71:139-164.

2. Scheinberg IH, Sternlieb I. Wilson's disease. In: Smith LH Jr, editor. Major problems in internal medicine, Vol. 23. Philidelphia: W.B. Saunders; 1984.

3. Schilsky ML. Wilson disease: Genetic basis of copper toxicity and natural history. Seminars in Liver Disease 1996;16:83-95.

4. Bush JA, Mahoney JP, Markowitz H, Gubler CJ, Cartwright GE, Wintrobe MM. Studies on copper metabolism. XVI. Radioactive copper studies in normal subjects and in patients with hepatolenticular degeneration. J Clin Ivest 1955;34:1766-1778.

5. Frommer DJ. Defective biliary excretion of copper in Wilson's disease. Gut 1974;15:125-29.

6. Gibbs K, Walshe JM. Biliary excretion of copper in Wilson's disease. Lancet 1980;2:538-39.

7. Bull PC, Thomas GR, Rommens JM, Forbes JR, Cox DW. The Wilson's disease gene is a putative copper transporting P-type ATPase similar to the Menkes gene. Nature Genet 1993;5:327-337.

8. Tanzi RE, Petrukhin K, Chernov I, Pellequer JL, Wasco W, Ross B, et al. The Wilson disease gene is a copper transporting ATPase with homology to the Menkes disease gene. Nature Genet 1993;5: 44-50.

9. Yamaguchi Y, Heiny ME, Gitlin JD. Isolation and characterization of a human liver cDNA as a candidate gene for Wilson disease. Biochem Biophys Res Commun 1993;197:271-277. 
10. Iyengar V, Brewer GJ, Dick RD, Owyang C. Studies of cholecystokinin-stimulated biliary secretions reveal a high molecular weight copper-binding substance in normal subjects that is absent in patients with Wilson's disease. J Lab Clin Med 1988;111:267-274.

11. Fink JK, Hedera P, Brewer GJ. Hepatolenticular degeneration (Wilson's disease). Neurologist $1995 ; 171-185$.

12. Kayser B. Ueber einen Fall von angeborener grünlicher Verfärbung der kornea. Klin Mbl Augenheilk 1902;40:22-25.

13. Fleischer B. Zwei weitere Fälle von grünliche Verfärbung der Kornea. Klin Mbl Augenheilk 1903; 41:489-491.

14. Walshe JM. Penicillamine. A new oral therapy for Wilson's disease. Am J Med 1956;21:487-495.

15. Walshe JM. Treatment of Wilson's disease with trientine (triethylene tetramine) dichloride. Lancet 1982;1:643-47.

16. Brewer GJ, Brewer LF, Prasad AS. Suppression of irreversibly sickled erythrocytes by zinc therapy in sickle cell anemia. J Lab Clin Med 1977;90:549-554.

17. Brewer GJ, Schoomaker EB, Leichtman DA, Kruckleberg WC, Brewer LF, Myers N. The uses of pharmacologic doses of zinc in the treatment of sickle cell anemia. In: Brewer GJ, Prasad AS, editors. Zinc metabolism: Current aspects in health and disease. New York: Allan R. Liss; p 241-258.

18. Prasad AS, Brewer GJ, Schoomaker EB, Rabbini P. Hypocupremia induced by zinc therapy in adults. JAMA 1978;240:2166-2168.

19. Brewer GJ, Hill GM, Prasad AS, Cossack ZT, Rabbani P. Oral zinc therapy for Wilson's disease. Ann Intern Med 1983; 99:314-320.

20. Hill GM, Brewer GJ, Prasad AS, Hydrick CR, Hartmann DE. Treatment of Wilson's disease with zinc: I. Oral zinc therapy regimens. Hepatology 1987;7:522-528.

21. Hill GM, Brewer GJ, Juni JE, Prasad AS, Dick RD. Treatment of Wilson's disease with zinc: II. Validation of oral ${ }^{64}$ copper uptake with copper balance. Am J Med Sci 1986;12:344-49.

22. Brewer GJ, Hill GM, Dick RD, Nostrant TT, Sams JS, Wells JJ, Prasad AS. Treatment of Wilson's disease with zinc: III. Prevention of reaccumulation of hepatic copper. J Lab Clin Med 1987;109: $526-531$

23. Brewer GJ, Hill GM, Prasad AS, Dick RD. Treatment of Wilson's disease with zinc: IV. Efficacy monitoring using urine and plasma copper. Proc Soc Exper Biol Med 1987;7:446-455.

24. Yuzbasiyan-Gurkan V, Brewer GJ, Abrams GD, Main B, Giacherio D. Treatment of Wilson's disease with zinc: V. Changes in serum levels of lipase, amylase and alkaline phosphatase in Wilson's disease patients. J Lab Clin Med 1989;114:520-526.

25. Brewer GJ, Yuzbaysian-Gurkan V, Lee D-Y, Appelmann H. The treatment of Wilson's disease with zinc: VI. Initial treatment studies. J Lab Clin Med 1989;114:633-638.

26. Lee D-Y, Brewer GJ, Wang Y. The treatment of Wilson's disease with zinc: VII. Protection of the liver from copper toxicity by zinc induced metallothionein in a rat model. J Lab Clin Med 1989; 114:639-645.

27. Brewer GJ, Yuzbasiyan-Gurkan V, Dick R. Zinc therapy of Wilson's disease: VIII. Dose response studies. Trace Elem in Exp Med 1990;3:227-234.

28. Brewer GJ, Yuzbasiyan-Gurkan V, Johnson V. The treatment of Wilson's disease with zinc: IX. Response of serum lipids. J Lab Clin Med 1991;118:466-470.

29. Yuzbasiyan-Gurkan V, Grider A, Nostrant T, Cousins RJ, Brewer GJ. The treatment of Wilson's disease with zinc: X. Intestinal metallothionein induction. J Lab Clin Med 1992;120:380-386.

30. Brewer GJ, Yuzbasiyan-Gurkan V, Johnson V, Dick RD, Wang Y. Treatment of Wilson's disease with zinc: XI. Interaction with other anticopper agents. J Am Coll Nut 1993;12:26-30.

31. Brewer GJ, Yuzbasiyan-Gurkan V, Johnson V, Dick RD, Wang Y. Treatment of Wilson's disease with zinc: XII. Dose regimen requirements. Am J Med Sci 1993;305:199-202.

32. Brewer GJ, Dick RD, Yuzbasiyan-Gurkan V, Johnson V, Wang Y. Treatment of Wilson's disease with zinc: XIII. Therapy with zinc in presymptomatic patients from the time of diagnosis. J Lab Clin Med 1994;123:849-858.

33. Brewer GJ, Johnson V, Kaplan J. Treatment of Wilson's disease with zinc: XIV. Studies of the effect of zinc on lymphocyte function. J Lab Clin Med 1997;129:649-652.

34. Brewer GJ, Dick RD, Johnson V, Brunberg JA, Kluin KJ, Fink JK. Treatment of Wilson's disease with zinc: XV. Long-term follow-up studies. J Lab Clin Med 1998;132:264-278. 
35. Brewer GJ, Dick RD, Johnson V, Fink JK, Kluin KJ, Daniels S. Treatment of Wilson's disease with zinc: XVI. Treatment during the pediatric years (submitted).

36. Oelshlegel FJ, Brewer GJ. Absorption of pharmacological doses of zinc. In: Brewer CJ, Prasad AS, editors. Zinc metabolism: Current aspects in health and disease. New York: Alan R. Liss; 1977. p 299-316.

37. Henderson LM, Brewer GJ, Dressman JB, Swidan SZ, DuRoss DJ, Adair CH, Barnett JL, Berardi $\mathrm{RR}$. Effect of intragastric $\mathrm{pH}$ on the absorption of oral zinc acetate and zinc oxide in young healthy volunteers. J Parenteral and Enteral Nutr 1995;19:393-397.

38. Menard MP, McCormick CC, Cousins RJ. Regulation of intestinal metallothionein biosynthesis in rats by dietary zinc. J Nutr 1981;111:1351-1361.

39. Oestreicher P, Cousins RJ. Copper and zinc absorption in the rat: Mechanism of mutual antagonism. J Nutr 1985;115:159-166.

40. Hall AC, Young BW, Bremner I. Intestinal metallothionein and the mutual antagonism between copper and zinc in the rat. J Inorg Biochem 1979;11:57-66.

41. Keen CL, Lonnerdal B, Hurley LS. Teratogenic effect of copper deficiency and excess. In: Sorenson JRJ, editor. Inflamatory diseases and copper. Clifton, NJ: Humana Press; 1982. p 109-119.

42. Mjolnerod OK, Dommerud SA, Rasmussen K, Gjeruldesen ST. Congenital connective tissue defect probably due to D-penicillamine treatment in pregnancy. Lancet 1971;1:673-675.

43. Solomon L, Abrams G, Dinner M, Berman L. Neonatal abnormalities associated with Dpenicillamine treatment during pregnancy. N Engl J Med 1977;296:54-55.

44. Food and Drug Administration. Teratogenic evaluation of FDA 71-49 (zinc sulfate). Food and Drug Research Laboratories, Inc. Prepared for Food and Drug Administration, United States Department of commerce Publications PD-221 805, February 1973, and PB 267, June 1974.

45. Black MR, Medeiros DM, Bruneti E, Welke R. Zinc supplements and serum lipids in young adult white males. Am J Clin Nutr 1988;47:970-975.

46. Chandra RK. Excessive intake of zinc impairs immune responses. JAMA 1984;252:1443-1446.

47. Hooper PL, Visconti L, Garry PJ, Johnson GE. Zinc lowers high-density lipoprotein-cholesterol levels. JAMA 1980;244:1960-1961.

48. Shimon I, Sela BA, Moses B, Doley E. Hemolytic episode in a patient with Wilson's disease treated with zinc. Israel J Med Sci 1993;29:646-147.

49. Walshe JM, Munro NAR. Zinc-induced deterioration in Wilson's disease aborted by treatment with penicillamine, dimercaprol, and a novel zero copper diet. Arch Neurol 1995;52:10-11.

50. Schouwink, G. De hepatocecerebrale degeneratie, met een onderzoek naar de zonkstrofwisseling. MD thesis (with a summary in English, French, and German). University of Amsterdam; 1961.

51. Hoogenraad TU, Koevoet R, De Ruyter Korver EGWM. Oral zinc sulfate as long-term treatment in Wilson's disease (hepatolenticular degeneration). Eur Neurol 1979;18:205-211.

52. Hoogenraad TU, Van den Hamer CJA, Koevoet R, De Ruyter Korver EGWM. Oral zinc in Wilson's disease. Lancet 1978;2:1262-63.

53. Hoogenraad TU, Van Hattum J, Van den Hamer CJA. Management of Wilson's disease with zinc sulfate. Experience in a series of 27 patients. J Neurol Sci 1987;77:137-146.

54. Brewer GJ, Terry CA, Aisen AM, Hill GM. Worsening of neurologic syndrome in patients with Wilson's disease with initial penicillamine therapy. Arch Neurol 1987;44:490-493.

55. Ferguson WS, Lewis AL, Waterson SJ. The teart pastures of Somerset, I: The cause and cure of teartness. J Agri Sci 1943;33:44.

56. Dick AT, Bull, LB. Some preliminary observations on the effect of molybdenum on copper metabolism in herbivorous animals. Aust Vet J 1945; 21:70-72.

57. Miller RF, Engel RW. Interrelations of copper, molybdenum and sulfate sulfur in nutrition. Fed Proc 1960;19:666-667.

58. Marcilese Ammerman CB, Valsecchi RM, Dunavant BG, Davis GK. Effect of dietary molybdenum and sulfate upon copper metabolism in sheep. J Nutr 1969;99:177-183.

59. Mills CF, Monty KJ, Ichihara A, Pearson PB. Metabolic effects of molybdenum toxicity in the rat J Nutr 1958;65:129-142.

60. Cox DH, Davis GK, Shirley RL, Jack FH. Influence of excess dietary molybdenum on rat and calf liver and heart enzymes. J Nutr 1960; 70:63-68.

61. Dick AT, Dewer DW, Gawthorne JM. Thiomolybdates and the copper-molybdenum-sulfur interaction in ruminant nutrition. J Agr Sci 1975;85:567-568. 


\section{Wilson's Disease}

62. Mason J. The biochemical pathogenesis of molybdenum-induced copper deficiency syndrome in ruminants: Towards the final chapter. Ir Vet J 1990;43:18-21.

63. McQuaid A, Mason J. A comparison of the effects of penicillamine, trientine, and trithiomolybdate on [25S]-labeled metallothionein in vitro: The implications for Wilson's disease therapy. J Inorgan Biochem 1991;41:87-92.

64. Mills CF, El-Gallad TT, Bremner I. Effects of molybdate, sulfide, and tetrathiomolybdate on copper metabolism in rats. J Inorgan Biochem 1981;14:189.

65. Bremner I, Mills CF, Young BW. Copper metabolism in rats given di- or trithiomolybdates. J Inorgan Biochem 1982;16:109.

66. Mills CG, El-Gallad TT, Bremner I et al. Copper and molybdenum absorption by rats given ammonium tetrathiomolybdate. J Inorgan Biochem 1981;14:163.

67. Gooneratne SR, Howell JM, Gawthorne JM. An investigation of the effects of intravenous administration of thiomolybdate on copper metabolism in chronic Cu-poisoned sheep. Br J Nutr 1981;46: 469.

68. Brewer GJ, Dick RD, Yuzbasiyan-Gurkin V, Tanakow R, Young AB, Kluin KJ. Initial therapy of patients with Wilson's disease with tetrathiomolybdate. Arch Neurol 1981;48:42-47.

69. Brewer GJ, Dick RD, Johnson V, Wang Y, Yuzbasiyan-Gurkin V, Kluin KJ, Fink JK, Aisen A. Treatment of Wilson's disease with ammonium tetrathiomolybdate: I. Initial therapy in 17 neurologically affected patients. Arch Neurol 1994;51:545-554.

70. Brewer GJ, Johnson V, Dick RD, Wang Y, Kluin KJ, Fink JK, Brunberg JA. Treatment of Wilson Disease with ammonium tetrathiomolybdate: II. Initial therapy in 33 neurologically affected patients and follow-up with zinc therapy. Arch Neurol 1996;53:1017-1025.

71. Nazer H, Ede RJ, Mowat AP, Williams R. Wilson's disease: clinical presentation and use of prognostic index. Gut 1986;27:1377-1381. 